Simon P. Philbin

\title{
Applying an Integrated Systems Perspective to the Management of Engineering Projects
}

\begin{abstract}
Engineering projects can be subject to significant complexity, which may result in a number of issues and challenges that need to be addressed throughout the project life-cycle. Traditionally projects have been viewed according to the so called "iron triangle," i. e., achievement of project milestones according to schedule, cost and quality targets. While these targets are fundamentally important to the performance of engineering projects, it is possible to view projects on a systemic level in order to allow an adequate focus on all the underpinning factors that have the potential to influence the performance of projects. Consequently, a management framework has been developed that is based on an integrated systems perspective of engineering projects, where the performance of projects is a function of six contributing sub-systems that are: process, technology, resources, knowledge, culture and impact.
\end{abstract}

Keywords: integrated systems perspective, engineering projects, management

\section{Introduction}

The sub-systems can be broadly considered as being part of three integrated levels, which are as follows: project infrastructure (resources and technology sub-systems), project organization (process and knowledge sub-systems) and project environment (culture and impact sub-systems). This framework has been developed through building on a comprehensive literature review of the critical success factors for engineering project management. The integrated systems perspective is discussed through reporting the findings from two illustrative case studies that highlight the utility of the approach. Both case studies involved facilities

Manuscript received June 3, 2015; accepted June 23, 2015

Simon P. Philbin ( $($ )

Imperial College London, London SW7 2AZ, UK

Email: s.philbin@ imperial.ac.uk development projects that were undertaken at a university in the UK and included significant technical risk.

The first project involved the refurbishment and enhancement of a large laboratory in order to accommodate a new high pressure experimental research facility. This project was carried out over a three-year time-frame and involved a close partnership between the manufacturer based in the USA and partner companies in the UK as well as the host university. The project employed systems engineering approaches as well as the failure mode and effects analysis (FMEA) technique. The second case study involved completion of a feasibility and design project for the upgrade and enhancement of a medical research laboratory that contained several pieces of advanced medical scanning equipment. This one-year project involved extensive consultation with medical practitioners in order to derive the clinical needs for the facility, which was driven through a formal requirements capture process. This approach enabled the resulting engineering and construction works to be carried out in a timely fashion.

The case studies provide managerial insights that are related to the framework but also position the approach in the context of industrial applications for engineering management. Furthermore, the case studies allow instantiations of emergent behavior to be identified and this is positioned in regard to general systems theory. The paper concludes with a series of research implications relating to the systemic nature of projects as well as suggested areas for future research included the data and information requirements for pursuing this research agenda.

Engineering projects can be subject to significant complexity, which may result in a number of issues and challenges that need to be addressed throughout the project life-cycle. This complexity is associated with a range of factors, some of which are a function of the internal project artifacts and others are associated with the external project environment. In the former case, for instance, involving construction project management, internal project artifacts may include the level of inter-dependency between different work sections, such as architecture, structural 
engineering, mechanical and electrical (M\&E), quantity surveying and so on. Factors from the external environment in this scenario could range from the impact of changes to international design and construction standards as well as the availability of resources from the surrounding region, such as electrical installation workers. These internal and external dynamics, which can be viewed from a systems perspective, result in engineering projects encountering complexity that if not adequately identified and managed will can in result significant problems.

In the construction sector, there are many high profile projects that have encountered difficulties. The "Big Dig" project (Ring, 2000) in Boston, USA was delivered at a cost of approximately $\$ 15 \mathrm{Bn}$, which was seven times the original budget. The project related to the construction of a major underground arterial road system through central Boston and while it has undoubtedly helped ease congestion in the city, from a financial perspective the project would appear to have been a failure. In the UK, Heathrow Airport's Terminal 5 project encountered significant difficulties when the facility was first opened. This time the construction proceeded according to project plans and the new terminal was opened within the schedule and cost targets, however, initial operations were hampered by a number of issues, such as problems with the baggage handling system as well as a lack of baggage handling staff to operate the system (Brady \& Davies, 2010). These failures point to the complex and systemic nature of projects, where there is a need to gain an effective understanding of the broader context of projects.

Projects in other sectors also face difficulties, such as research and development (R\&D) projects, where the project success has been found to be highly sensitive to technological uncertainty (Sadeh, Dvir, \& Shenhar, 2000). Information systems (IS) projects can have a particularly high failure rate (Standish Group, 1995 and 2009) through a combination of budgets being exceeded along with missed deadlines and schedule slippage or through a failure to meet user requirements. Moreover, IS projects may fail to produce the required technical functionality for the system, or alternatively such technical levels can be achieved but there may be a lack of user acceptance that ultimately results in the project failing to deliver a new IS capability. User acceptance can be linked to broader factors, such as the culture of the working environment where the project is being implemented; systemic drivers, both internally and externally driven, therefore have the potential to introduce additional risk for engineering projects beyond those initially identified in the project risk register.

Traditional project management is focused on controlling projects according to schedule, cost and quality or performance targets, which is often regarded as the so called "iron triangle." While achieving project milestones according to these reference points clearly remains an integral feature of project management, the question arises: Can the complexity that emerges from engineering projects be managed through an integrated systems perspective? This paper will therefore seek to address this question through deriving a conceptual framework based on systems thinking, which will be discussed in the context of two support case studies.

The research reported in this paper builds on earlier work that established an integrated systems view of engineering projects (Philbin \& Kennedy, 2014). Although the conceptual model developed previously also derives the systems view through integrating process, technology, resources, knowledge, culture and impact, it is nevertheless focused on describing a new diagnostic framework and health check tool for engineering and technology projects. Conversely, the focus of the research in this current paper is toward proposing an integrated systems perspective of engineering projects and with additional consideration of two supporting case study investigations as well as development of an agenda for future research.

\section{Literature review}

As mentioned previously, ensuring projects realize schedule, cost and quality targets (Jha \& Iyer, 2007) according to a defined project management approach is clearly important for engineering projects and the performance of projects has been associated with the maturity of the project management methodology that is utilized (Jin, Chai, \& Tan, 2014). Work by Chan, Scott, \& Chan, (2004) on construction projects identified that the use of project management procedures was one of five main groups of independent variables that may impact on project performance with the other four groups being: project-related factors, project management actions, human-related factors and the external environment. The adoption of processes and procedures can also be viewed through project organizational hierarchies, with related projects being part of larger programs of work, which in turn are part of portfolios. Indeed some studies have highlighted how there is a correlation between the use of project portfolio management (PPM), through increased adoption of software tools developed to assist and automate the project management process, with a reduction in project related problems (Reyck, 2005). Other standardized project management tools include risk management procedures (Raz \& Michael, 2001), which have been understood and applied for many years and continue to be important in regard to capturing and controlling project risk.

Consequently, the adoption and implementation of processes including standardized procedures is an important determinant of project success. This implementation will also rest on the availability and use of information and 
communications technology (ICT), which can be used to facilitate, for instance, critical path analysis for planning and control, resource scheduling for planning, and earned value analysis for control (Liberatore, Pollack-Johnson, \& Smith, 2001). ICT is needed to capture project information and data on schedule, budget and specification performance but it can also be essential for ensuring effective communication between project team members (Ahuja, Yang, \& Shankar, 2009). This communication of project information supports coordination and collaboration within projects that is essentially facilitated by ICT. Some authors have identified the need for management processes to be modified to take account of advances in ICT for the architecture, engineering and construction industries (Froese, 2010). Moreover, communication and sharing of project related information can be achieved through a number of different tools and software applications but once this has been done there is the need to process the information. Consequently, the design of appropriate ICT platforms that provide assistance in terms of data analysis tools and through presenting technical and management solutions to key project personnel has been advocated (Pena-Mora \& Dwivedi, 2002). Additional options include the use of web-based project management tools, although such systems are still under development and evaluation (Nitithamyong \& Skibniewski, 2006).

Information and communications technology application in project management as well as process adoption will often largely rest on the effectiveness of resources that are employed across the project. Effective project leadership is pivotal to project performance (Turner \& Muller, 2005) and the project manager will need to have the required skills, competencies, understanding and experience of the project environment to be successful (Brill, Bishop, \& Walker, 2006). An appreciation of the technical aspects of the project is required but this needs to be augmented by appropriate soft skills. Indeed research into the human factors of project management has indicated that project managers and engineers with higher levels of emotional intelligence tend to exhibit greater levels of delegating, open communication, and proactive behavior that tend to generate positive outcomes for the organization (Sunindijo, Hadikusumo, \& Ogunlana, 2007). The effective deployment of resources can also have a significant impact on project success and implementation of tools and techniques that allow project managers to efficiently allocate limited resources across projects will likely lead to higher levels of project performance (Jaselskis \& Ashley, 1991). The effective allocation of resources becomes even more of an important consideration in the case where organizations are required to implement multiple projects concurrently that have a shared resource base (Engwall \& Jerbrant, 2003). ICT solutions can help project managers to balance the needs of multiple competing projects although organizational challenges remain where the resource base is not able to fully accommodate the required level of project activity. In this scenario, the project manager may consider outsourcing or working with other project partners to share the project workload.

Effective management of resources across projects along with the use of ICT (e. g., scheduling tools such as Microsoft Project) is of course predicated on the availability of project data and information (Schwalbe, 2013). Furthermore, the use of information that is generated by a project may be related to the knowledge management practice of the organizations concerned, where knowledge management practice in conjunction with ICT application can result in improved performance of projects in regard to schedule and cost success as well as quality and safety (Yang, Chen, \& Wang, 2012). The availability of data and information within projects is important and when processed such knowledge will be needed to support a number of project management processes, such as risk management (Alhawari, Karadsheh, Talet, \& Mansour, 2012). In other studies, research on the automotive sector has highlighted how establishing communities of practice (i. e., working groups that have common interests) can help support project knowledge management (Johansson, Moehler, \& Vahidi, 2013). Knowledge management for information technology projects may be considered as enabling the creation and alignment of three types of project-based knowledge that are needed to result in the desired business outcomes, which are technical design knowledge, organizational change knowledge and business value knowledge (Reich, Gemino, \& Sauer, 2012). Adopting a broad or holistic view of the knowledge that is generated during a project as well as the knowledge requirements of engineering project is therefore a desirable objective.

The context in which project resources are administered and delivered can be related to the culture of the organizations involved, which includes the level of project management maturity (Yazici, 2009). Benefits that have been reported for the integration of a project management culture with an organization's more traditional line management culture include improved responsiveness and flexibility (Firth \& Krut, 1991). The cultural dimension includes the level of trust between the project workers as well as the level of information sharing and creative teamwork (Kadefors, 2004). Ensuring that projects are delivered in such an environment is an important consideration for all projects and not just those involving engineering. In this context effective project leadership is required so that boundaries are understood and the appropriate levels of trust can be developed within the project (Sabherwal, 1999). Projects are however by their nature temporary organizational abstractions and there is only a limited period of time available to develop trust between project workers, where the initial opinions of the 
people working on the project can be important in shaping the project's final outcome (Munns, 1995). In this scenario, the initial opinions can potentially cause a movement of the project into a spiral of increasing or decreasing trust, depending on whether the opinions were positive or negative respectively. In the latter case, project managers need to take care especially if the initial attitude is one of mistrusting the other parties and in this case pursuing project strategies that encourage a positive environment will be needed.

Ensuring projects generate the required knowledge can be viewed in terms of the overall value proposition for a project, which is related to the value that will be delivered according to the needs of stakeholders (Frow \& Payne, 2011). Projects that are successful will meet the required milestones, which will be aligned to the value drivers for the project stakeholders and ultimately delivery according to these value drivers ensures projects result in impact for such stakeholders. For instance, completion of a design project for a new type of turbine blade by an aero-engine manufacturer that results in the company being able to extend the operational life of an engine beyond the level achieved by competitors. This is a direct form of impact by such a project. Project impact may also result in additional business areas being created upon completion of the project, which can require a longer time-frame to be adopted for measuring the success of projects if such additional benefits are to be fully captured. Projects that result in new product development (NPD) for companies contribute directly to the company's competitive position and the product development life-cycle has been linked to the product complexity (Griffin, 1997); in this scenario projects that allow product complexity to be minimized will have a direct effect on reducing the product development life-cycle thereby having an impact on the company's competitive position. Projects can also result in broader impact that provides societal benefits, such as improved energy efficiency (Sivarajah, Lee, Irani, \& Weerakkody, 2014). In regard to research projects focused on health-care (e. g., drug discovery), there is an increasing need to translate the knowledge that is generated and the supporting evidence into improved health-care practice and this represents a further example of wider impact arising from a project (Straus, Tetroe, \& Graham, 2013). Additionally, completion of projects may result in other forms of impact, such as skills development and improved competencies of project team members arising from project-based learning (Ayas \& Zeniuk, 2001).

The literature review has identified six main areas or critical success factors that contribute to the performance of engineering projects. These six areas collectively represent a systems perspective of projects since they provide a holistic consideration of the wider landscape of engineering project management, in terms of the process-driven, organizational-based and human-based factors. Table 1 provides a summary of the findings from the literature review.

\section{Developing an integrated systems perspective}

There have been other studies that have proposed the application of systems approaches and systems engineering to the management of projects (Kerzner, 2013; Love, Holt, Shen, Li, \& Irani, 2002; Lyneis \& Ford, 2007; Sage \& Rouse, 2009), which highlights the utility of this approach. Indeed research from the UK has advocated the application of systems engineering to a range of different areas, including the management of technology projects (Philbin, 2008a; Philbin, 2011), management of bids and proposals (Philbin, 2008b) and safety engineering (Philbin, 2010). These applications seek to gain an improved understanding of complex technical and engineering instantiations through leveraging the tools and techniques of systems thinking and systems engineering practices. Such practices include requirements capture and engineering, integrated system design, development of system architectures, system modeling, system integration, understanding emergent properties and system-of-systems viewpoints. Moreover, previous studies by Frank (2000) hasdescribed the concept of engineering systems thinking that incorporates a number of underlying features, which are as follows: ability to see the "big picture"; implementation of overall management considerations; acquisition and use of interdisciplinary knowledge; analysis of customer needs and internal capabilities; use of underpinning systems knowledge; understanding of synergies and emergent properties; ability to challenge existing approaches; creativity and creative management.

Work by Dvir and Shenhar (2007) highlighted the merit of considering project management from a systems viewpoint, which proposed a model based on five primary dimensions. The dimensions are as follows: project efficiency, i. e., meeting budget and schedule requirements; impact on the customer, i. e., achieving the stated requirements for the project, including customer benefits, satisfaction and arising loyalty; impact on the team, i. e., the impact the project has on team members including levels of satisfaction, retention and resulting personal growth; business results, i. e., the outcome of the project in terms of any return on investment, market share or growth that is achieved; preparation for the future, i. e., how project deliverables result in the development of new technologies, markets and capabilities.

Therefore, there is precedence in the literature for adopting a systemic view of projects. Accordingly, the six critical success factors for engineering projects identified by the literature review that represent a holistic 
Table 1

Summary of Critical Success Factors for Engineering Projects Identified by Literature Review

\begin{tabular}{|c|c|c|}
\hline $\begin{array}{l}\text { Critical success } \\
\text { factor }\end{array}$ & References from literature review & Definition of critical success factor \\
\hline$\overline{\text { Process }}$ & $\begin{array}{c}\text { Jha \& Iyer, } 2007 \\
\text { Jin, Chai, \& Tan, } 2014 \\
\text { Chan, Scott, \& Chan, } 2004 \\
\text { Reyck, } 2005 \\
\text { Raz \& Michael, } 2001\end{array}$ & $\begin{array}{l}\text { Management processes undertaken in a structured manner in order to enable delivery of the } \\
\text { project requirements according to specified project management guidelines or protocols }\end{array}$ \\
\hline Technology & $\begin{array}{c}\text { Liberatore, Pollack-Johnso, \& Smith, } 2001 \\
\text { Ahuja, Yang, \& Shankar, } 2009 \\
\text { Froese, } 2010 \\
\text { Pena-Mora \& Dwivedi, } 2002 \\
\text { Ntithamyong \& Skibniewski, } 2006\end{array}$ & $\begin{array}{l}\text { ICT employed across the project to support delivery of project milestones as well as } \\
\text { knowledge management including related IT systems accessed by project team members }\end{array}$ \\
\hline Resources & $\begin{array}{c}\text { Turner \& Muller, } 2005 \\
\text { Brill, Bishop, \& Walker, } 2006 \\
\text { Sunindijo, Hadikusumo, \& Ogunlana, } 2007 \\
\text { Jaselskis \& Ashley, } 1991 \\
\text { Engwall \& Jerbrant, } 2003\end{array}$ & $\begin{array}{l}\text { Project staff and infrastructure required to undertake management and technical work to support } \\
\text { project delivery. This includes project management and other staff involved in project governance } \\
\text { and where necessary other project stakeholders }\end{array}$ \\
\hline Knowledge & $\begin{array}{c}\text { Schwalbe, } 2013 \\
\text { Yang, Chen, \& Wang, } 2012 \\
\text { Alhawari, Karadsheh, Talet, \& Mansour, } \\
2012 \\
\text { Johansson, Moehler, \& Vahidi, } 2013 \\
\text { Reich, Gemino, \& Sauer, } 2012\end{array}$ & $\begin{array}{l}\text { Data and information that is processed and generated by project resources through use of project } \\
\text { technology and according to processes used across the project. Knowledge includes management } \\
\text { and engineering information as well as the insights and understanding gained from delivery of the } \\
\text { project }\end{array}$ \\
\hline Culture & $\begin{array}{c}\text { Yazici, } 2009 \\
\text { Firth \& Krut, } 1991 \\
\text { Kadefors, } 2004 \\
\text { Sabherwal, } 1999 \\
\text { Munns, } 1995\end{array}$ & $\begin{array}{l}\text { The patterns of working across the project, including the level of openness and sharing of project } \\
\text { knowledge by the project resources. This includes the social dimensions of the project and its } \\
\text { surrounding environment, such as trust and norms of reciprocity between team members }\end{array}$ \\
\hline Impact & $\begin{array}{c}\text { Frow \& Payne, } 2011 \\
\text { Griffin, } 1997 \\
\text { Sivarajah, Lee, Irani, \& Weer-akkody, } 2014 \\
\text { Straus, Tetroe, \& Graham, } 2013 \\
\text { Ayas \& Zeniuk, } 2001\end{array}$ & $\begin{array}{l}\text { The overall outcomes generated by the project, which includes delivery of the project milestones } \\
\text { as well as wider (holistic) benefits arising. The benefits can include new business generation, } \\
\text { societal, environmental as well as skills enhancement and human resources development }\end{array}$ \\
\hline
\end{tabular}

view can be conceptualized as part of an integrated systems perspective. The integrated systems perspective has been synthesized through interpretation of the findings from the literature review and the definitions provided in Table1. Figure 1 provides the conceptual model for the integrated systems perspective of engineering projects.

This framework views a project as a system, where the critical success factors are depicted as six sub-systems that contribute to the overall performance of the project. Factors that are outside of the influence or are not directly connected with the project are external systems, e. g., availability of raw materials. Furthermore, in order for an external factor to become associated with the project, it needs transition the project or system boundary through a dynamic interaction, e. g., when a contract is placed to cover the provision of such raw materials.

\section{Case study investigations}

Both case studies involved engineering projects at Imperial College (the university), which resulted in the provision of 


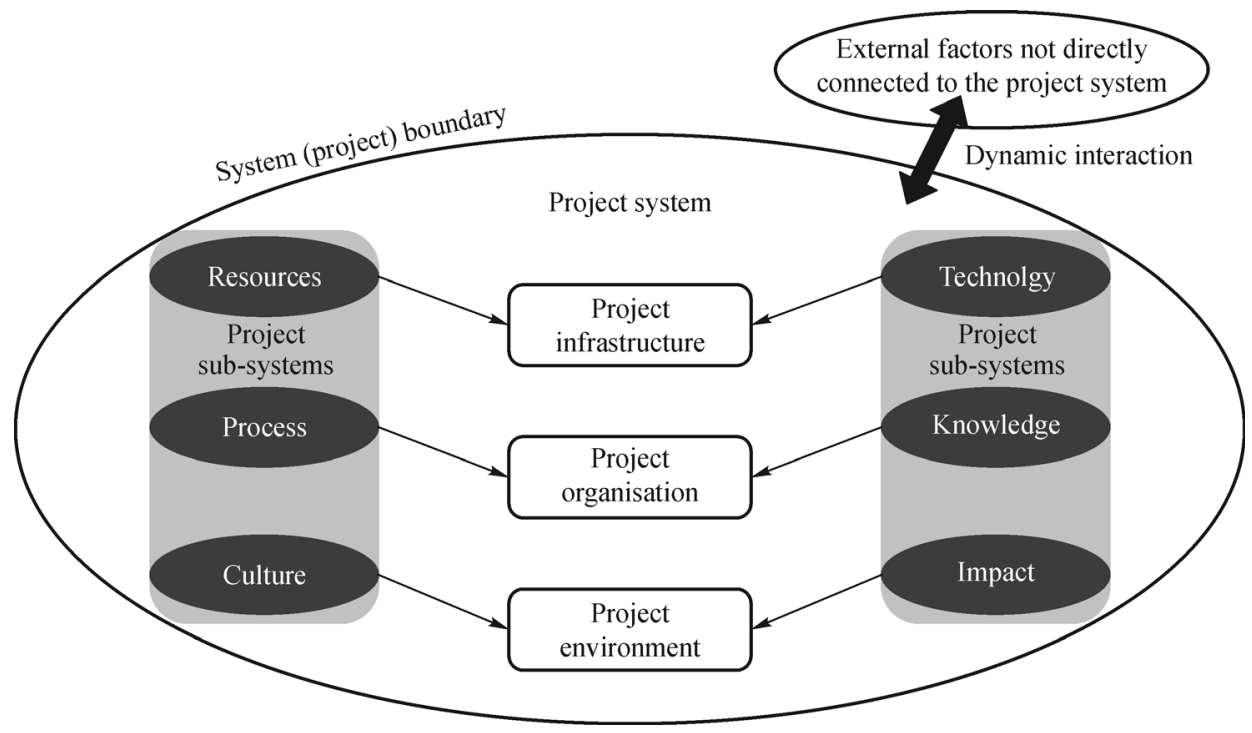

Figure 1. Conceptual model for integrated systems perspective of engineering projects.

new experimental research facilities. The case studies have been investigated as part of a process of reflective inquiry (Schon, 1983), involving consideration of both qualitative information and quantitative data. This process allows "sense-making" (Weick, Sutcliffe, \& Obstfeld, 2005) of the projects and an understanding of how the project activities were undertaken according to the sub-systems of the integrated systems perspective. Furthermore, sense-making provides a mechanism to allow practitioner oriented insights to be developed on how the engineering projects were managed.

The first case study (\# 1) involved a three-year project that focused on the development of a new experimental research facility at the university and the case study findings are summarized in Table 2 . The project involved the upgrade of an existing large laboratory through installation of complex M\&E services to house new highpressure experimental research equipment. The project also involved the design and manufacture of the equipment that was undertaken in USA. The equipment was designed for plate impact experiments to be conducted as part of research on how different metallic materials behave under high pressures.

The second case study (\# 2) involved a one-year project focused on the feasibility study and design of a medical scanning facility at a university hospital and the case study findings are summarized in Table 3 . The facility included scanning equipment, such as positron emission tomography (PET) and magnetic resonance imaging (MRI) systems for use as part of clinical research programs undertaken by the university. The project involved an engineering feasibility study of the facility, including M\&E and structural engineering design work, quantity surveying and various other technical activities. The feasibility study resulted in an engineering design of the new facility and this was accompanied by a business planning exercise to identity the revenue generation for the facility based on the expected clinical requirements for medical scanning.

\section{Conclusions}

This paper has described an integrated systems perspective of engineering projects through synthesizing the findings from a comprehensive literature review. The literature identified six main groups of critical success factors (namely process, technology, resources, knowledge, culture and impact), which can be viewed as sub-systems of the project system. According to this perspective the performance of engineering projects will be enhanced through pursuing an integrated set of strategies and activities across all six sub-systems; conversely, deficiency in one or more sub-systems would negatively impact on the performance of the project system.

Achievement of project milestones according to schedule, budgetary and quality targets remains of critical importance for project management but existing approaches do not always work. As reported in this paper, some engineering projects continue to encounter difficulties, cost overruns, missed milestones and cases where inadequate benefits are ultimately delivered to project stakeholders. The integrated systems perspective seeks to incorporate best practice on project management through a holistic and logical framework that can be applied by project engineers and project managers to tackle project complexity head-on. The utility of the framework has been explored through two case study investigation. Both case studies highlight how pursuing an integrated set 
Table 2

Summary of Case Study \# 1 Findings According to Sub-systems Areas

\begin{tabular}{ll}
\hline Sub-system & Key activities \\
\hline Processa & Project was managed according to PRINCE2TM international project management standard
\end{tabular}

Project reporting to senior management was via periodic highlight reports as well as deviations beyond the scope of the project communicated via exception reports

Use of standardized project documentation, such as project initiation document (PID), which was approved by the university portfolio review board

Business case assembled for the project, which included recognized business and financial practices, such as net present value (NPV) calculations for the expected investment by the project funder using the discounted cash flow technique

Other planning included resource profiling and project scheduling, which was undertaken at periodic stages during the project

Project risk register developed at start of project and updated periodically

Technology Microsoft Project TM used for Gantt chart preparation (project scheduling) to capture overall schedule, critical path analysis and key project dependencies

Project costing software used to develop initial budget and enterprise resource planning (ERP) software used to monitor and control project costs against the budget

Technical risk management via FMEA approach was administered through a Microsoft Excel TM spreadsheet template developed for use across the project

Regular video-conferencing between UK partners and suppliers based in USA

Other technologies used by engineering design team in support of the project

Resources Project resourcing included a project director with overall responsibility for project delivery. Project managers were assigned to manage the project at both the university and main industrial partner

Technical working group formed, which provided a multidisciplinary team of project members to support the project. The group included consultant engineering team (mechanical, electrical and structural engineers as well as quantity surveyor), technical staff (technician and academic staff from university as well as industrial staff), safety engineers, management representatives and administration staff

Project governance achieved through regular meetings of a project board, chaired by the project director but with other senior management representatives from the university

Knowledge Initial technical assessment of the project carried out by independent structural engineer contracted to undertake feasibility study of the facilities development project

FMEA technique developed to ensure engineering risks were captured from the early part of the project and necessary process controls were implemented in the final engineering design. FMEA process supported by multidisciplinary inputs from technical working group. FMEA worksheets used to formally capture engineering data and information related to the facility design, including operating conditions for the highpressure equipment and infrastructure engineering specifications

Systems integration exercise to ensure compatibility of procured equipment with laboratory services

Technical analysis and equipment operational modeling carried out to ensure compliance of equipment with European Union's Pressure Equipment Directive (PED)

Culture Initial meetings of technical working group hampered by lack of agreement on technical direction of project and social norms as well as poor team dynamics, which had not been fully established. Further meetings designed to have more overall direction from the meeting chair as well as structured discussions, which enabled social norms to be established

Trust was developed within the team due to the common approaches used as well as a shared sense of the technical challenges faced

UK team also established trust with suppliers based in USA, initially through face-to-face meetings and thereafter through regular videoconference meetings

Overall culture developed within the project was characterized as being open and honest, with regular sharing of information and communication across the project and with key project stakeholders

Impact Balanced scorecard approach adopted for the business planning stage of the project. Scorecard included financial perspective (based on NPV calculations on project investment), customer perspective (based on the number of $\mathrm{PhD}$ and MSc level students that would be able to use the new facility for research), internal process perspective (based on the availability of new equipment and related processes) and learning and growth perspective (based on the scientific areas to be investigated using the experimental research facility)

Wider impact for the industrial sponsor through supporting improved technical capabilities for new engineering systems

Establishment of the new research facility allowed the academic team to undertake research in new areas, which is analogous to company's developing new business areas. The teams involved with the project were able to develop new skills and competencies, for instance related to the engineering design process as well as the use of structured engineering risk tools such as FMEA 


\section{Table 3}

Summary of Case Study \# 2 Findings According to Sub-system Areas

Sub-system Key activities

Process

Project was managed according to PRINCE2TM international project management standard

Project reporting to senior management through regular meetings with key project stakeholders

Feasibility and design project approved by the university's portfolio review board

Business case assembled for the project, which included recognized business practices, such as business modeling based on revenue generation from medical scanning activities

Other planning included project scheduling and bench-marking studies, which compared modeled scanning costs with comparable data streams

Project risk analysis carried out on broad range of risk areas

Technology Microsoft Project TM used for Gantt chart preparation (project scheduling) to capture overall schedule, critical path analysis and key project dependencies

Project costing and other financial management through Microsoft Excel TM spreadsheets

Technical team employed various clinical related technologies (including diagnostic and testing systems) to support feasibility study

Other technologies used as part of facilities design process

Resources Project resourcing included a project director supported by a facilities project manager. The project director reported to a steering group that provided guidance on strategy

The project director provided overall leadership and was responsible for the business modeling while the project manager was responsible for operational management of the engineering feasibility study

Steering group was a multidisciplinary team representing different areas, such as senior leadership, facilities planning, finance, health S safety as well as general administration

Liaison with academic faculty members was through a series of individual consultations and this allowed a broad range of clinical academic staff to be engaged in the engineering design process

External engineering teams engaged to support detailed design, including M\&E engineers, quantity surveyor and safety engineer

Knowledge Improved understanding developed on how the clinical scanning facility would complement other facilities operated by the university, thereby allowing an overall view to be established for the entire scanning services offered across the university

Knowledge generated on the clinical research areas investigated through use of the medical scanning facility. This knowledge was acquired from the academic faculty consultations and covered areas such as neuroscience, cardiology, pharmacology and oncology

Information relating to sponsor needs was obtained, including potential scanning funding opportunities with research councils and charitable foundations

Data and information also acquired relating to the operation of the medical scanning equipment including operating conditions, throughput levels and maintenance regimes

Culture

During the initial meetings of the steering group a common understanding was developed of the project requirements including high-level technical details related to the medical scanning facility

Regular meetings allowed trust to be developed within the team and communications within the team were generally open and honest

The academic faculty consultations were conducted in an open manner, which enabled faculty members to share their needs in regard to current and future clinical research avenues being pursued and the corresponding medical scanning requirements

Overall culture developed within the project that was characterized as being supportive, with regular sharing of information and communication across the project and with key project stakeholders at the university

Impact completion of the feasibility and design stage project enabled an improved understanding to be gained on the need for medical scanning to support clinical research in several academic departments at the university

The project team developed enhanced skills and competencies, especially relating to business modeling techniques, including profiling different business scenarios and financial sensitivity analysis

The scanning facility was designed to provide an efficient and cost-effective clinical scanning service, which can be included as part of research proposals submitted to a range of medical funding organizations

Potential long-term societal benefits associated with improved health-care delivery arising from research projects that utilize the scanning facility 
of activities across the six sub-systems collectively support delivery of the projects. Case study \# 1 resulted in a state of the art experimental research facility being established at the university, for use by several academic and joint academic/industry research teams covering areas such as shock physics, mechanics of materials, earth sciences and aeronautics. Case study \# 2 resulted in completion of the feasibility and design stage for a medical scanning facility, which included extensive consultations with academic faculty to capture clinical needs as well as use of various business modeling techniques. The facility is able to support medical research across several areas, including neuroscience, cardiology, pharmacology and oncology.

It is interesting to note that both case studies exhibited cases of emergent behavior in regard to general systems theory (Gharajedaghi, 2011). In case study $\# 1$, the engineering design was supported by robust risk analysis and control involving use of the FMEA technique. This technique required appropriate data and information on the equipment (relating to the knowledge sub-system), according to the FMEA structured process approach (process subsystem), which was implemented by the project team members (resources sub-system) being supported by sharing of information across the team and with industrial partners (culture sub-system), thereby allowing a safe design to be produced (impact sub-system).

In case study \# 2, the facilities design was supported by a systematic approach to capturing clinical needs for the facility. This approach required collection of information on clinical areas to be researched (relating to the knowledge sub-system), which was enabled by the project director consulting with senior faculty members (resources subsystem) through a consultative and open approach (culture sub-system) that resulted in a facility available to support a range of therapeutic areas (impact sub-system). In both cases, there is synergy and interaction between the subsystems to create effect and value for the systems (and projects) as a whole. This further underscores the converse scenario, where a deficiency in one or more subsystems is likely to negatively impact on project performance and is therefore to be avoided where possible.

The research reported in this paper is focused toward being of relevance to practitioners involved in the management of engineering projects across different industrial sectors, such as construction and the built environment, manufacture (e.g., defense, aerospace and pharmaceutical) as well as other engineering applications. The integrated systems perspective provides a tool-kit that can be applied to different projects but ultimately the exact approach adopted (i.e., the specific configuration of strategies and activities across the six sub-systems) will be contingent on the project and organizational environment and circumstances. Therefore, there needs to be flexibility in regard to how the integrated systems perspective is applied. Additionally, both hard (technical) and soft (social or human factors) need to properly understood and accommodated in any implementation of the framework.

\section{Research implications and future work}

The research described in this paper has proposed and evaluated through case study methodology a new conceptual model based on an integrated systems perspective of engineering projects. Activities have been described according to the sub-systems of the project system for two case studies and instances of emergent behavior have been identified. Existing project management protocols and guidelines provide structured processes through stages and defined management structures; such approaches are useful but do they adequately capture the full scope of complexities associated with complex projects? Complexities across process, technology, resources, knowledge, culture and impact considerations. Furthermore, although the examples of emergent behavior can be described through considering the findings and outcomes of a project after it has been completed, could the interactions be identified (and codified) at the beginning of the project. These questions lead to the position that there is a whole series of research avenues and lines of enquiry that need to be properly investigated in order for a more complete picture to be derived for the management of complex engineering projects that exhibit high levels of risk but concurrently high levels of benefit. The implications arising from this paper are that the following research avenues need to be explored:

How do critical success factors (cf. sub-systems of the project system) interact and collectively contribute to the performance of engineering projects?

How can the project system be modeled while integrating quantitative data (e. g., relating to earned value analysis) with contextual and qualitative information (e. g., relating to the levels of trust exhibited by a project team)?

How can the optimal balance of activities across the subsystems of the project system be properly ascertained at the start of the project while recognizing the engineering requirements to be delivered as well as the environmental and organizational constraints?

Can a holistic set of metrics for measuring project success be defined that builds on the "iron triangle" through accommodating an integrated systems perspective of projects?

What are the new tools and techniques that need to be developed to support an integrated systems management of engineering projects?

In addition to these systemic research implications there are a number of more discrete areas of future research that have been identified for the six sub-systems of the project 
Table 4

Future Research Areas and Suggested Data and Information Requirements

\begin{tabular}{l} 
Project sub-system \\
\hline Process \\
How can the optimal balance of procedures be identified at the \\
outset of a new project?
\end{tabular}

Resources What is the project leadership skills needed to manage according to an integrated systems perspective?

How can resources be more effectively allocated across projects that have competing needs?

Can project decisions be modeled in real-time as a decision support tool?

Knowledge How can the project management knowledge be integrated with organization-level knowledge management systems?

How can knowledge from projects be configured to incorporate a socio-technical systems approach (i. e., managing hard and soft data)?

What knowledge needs to be understood to support the integrated systems perspective of project management?

Culture

How can the level of trust be measured for engineering projects?

How are projects influenced by organizational cultures?

Are certain types of cultures more, or less, suited to particular types of projects?

Impact

How can metrics be developed to address the integrated systems perspective of engineering projects?

How can achievement of "iron triangle" targets be reconciled (or balanced) against long-term, societal or broader stakeholder benefits?

What are the optimal mechanisms to support translation of research projects into societal benefits, i. e., environmental, sustainable energy or health-care

Data and information requirements

Project schedule, financial and performance data Process configurations and related protocol information

Data and information relating to the overall project requirements as well as environmental and organizational constraints

Probability data on likelihood of external events impacting projects (for deterministic studies)

Data and information on wider impact generated by projects Architectures and specifications of web-based project management systems

Architectures and specifications for mobile technologies (i.e., "apps") to support management of projects

Information on project leadership skills and competencies related to the integrated systems perspective of project management

Data and information on resource types for planning methodologies Project decision related data and information along with systems modeling techniques

Project-related data and information correlated with appropriate organizational data and information

Data and information on social characteristics of projects in addition to traditional hard (technical) data for engineering projects Data and information to allow improved knowledge management systems to be designed for projects

Data and information on the different drivers for trust within a project

Project cultural characteristics and determinants correlated with data and information for organizational cultures

Data and information on working patterns and behaviors, levels of openness and norms of reciprocity for certain project instantiations

Data and information relating to systemic impact and benefits for engineering projects, including long-term, societal or broader stakeholder benefits

Knowledge architectures to support translation of research projects and evidence-based outputs to improved practice and operational management

Data and information on project skills and competencies generated from adopting an integrated systems perspective system. Consequently, Table 4 provides recommended areas of future research along with the suggested data and information that researchers will need to acquire in order to pursue these investigations.

\section{References}

Ahuja, V., Yang, J., \& Shankar, R. (2009). Benefits of collaborative ICT adoption for building project management. Construction innovation: information, process. Management, 9, 323-340

Alhawari, S., Karadsheh, L., Talet, A.N., \& Mansour, E. (2012).
Knowledge-based risk management framework for information technology project. International Journal of Information Management, 32, 50-65

Ayas, K., \& Zeniuk, N. (2001). Project-based learning: building communities of reflective practitioners. Management Learning, 32, $61-76$

Brady, T., \& Davies, A. (2010). From hero to hubris-reconsidering the project management of Heathrow's Terminal 5. International Journal of Project Management, 28, 151-157

Brill, J. M., Bishop, M. J., \& Walker, A. E. (2006). The competencies and characteristics required of an effective project manager: a web-based Delphi study. Educational Technology Research and Development, 
54, 115-140

Chan, A. P., Scott, D., \& Chan, A. P. (2004). Factors affecting the success of a construction project. Journal of Construction Engineering and Management, 130, 153-155

Dvir, D., \& Shenhar, A. (2007). Reinventing Project Management: The Diamond Approach to Successful Growth and Innovation. Boston: Harvard Business School Press

Engwall, M., \& Jerbrant, A. (2003). The resource allocation syndrome: the prime challenge of multi-project management. International Journal of Project Management, 21, 403-409

Firth, G., \& Krut, R. (1991). Introducing a project management culture. European Management Journal, 9, 437-443.

Frank, M. (2000). Engineering systems thinking and systems thinking. Systems Engineering, 3, 163-168

Froese, T. M. (2010). The impact of emerging information technology on project management for construction. Automation in Construction, 19, 531-538

Frow, P., \& Payne, A. (2011). A stakeholder perspective of the value proposition concept. European Journal of Marketing, 45, 223-240

Gharajedaghi, J. (2011). Systems Thinking: Managing Chaos and Complexity: A Platform for Designing Business Architecture. Netherlands: Elsevier

Griffin, A. (1997). The effect of project and process characteristics on product development cycle time. Journal of Marketing Research, 24 35

Jaselskis, E. J., \& Ashley, D. B. (1991). Optimal allocation of project management resources for achieving success. Journal of Construction Engineering and Management, 117, 321-340

Jha, K. N., \& Iyer, K. C. (2007). Commitment, coordination, competence and the iron triangle. International Journal of Project Management, 25, 527-540

Jin, D., Chai, K. H., \& Tan, K. C. (2014). New service development maturity model. Managing Service Quality, 24, 86-116

Johansson, T., Moehler, R. C., \& Vahidi, R. (2013). Knowledge sharing strategies for project knowledge management in the automotive sector. Procedia: Social and Behavioral Sciences, 74, 295-304

Kadefors, A. (2004). Trust in project relationships - inside the black box. International Journal of Project Management, 22, 175-182

Kerzner, H. R. (2013). Project Management: a Systems Approach to Planning, Scheduling, and Controlling. New York: John Wiley \& Sons, Inc.

Liberatore, M. J., Pollack-Johnson, B., \& Smith, C.A. (2001). Project management in construction: software use and research directions. Journal of Construction Engineering and Management, 127, 101107

Love, P. E. D., Holt, G. D., Shen, L. Y., Li, H., \& Irani, Z. (2002). Using systems dynamics to better understand change and rework in construction project management systems. International Journal of Project Management, 20, 425-436

Lyneis, J. M., \& Ford, D. N. (2007). System dynamics applied to project management: a survey, assessment, and directions for future research. System Dynamics Review, 23, 157-189

Munns, A. K. (1995). Potential influence of trust on the successful completion of a project. International Journal of Project Management, 13, 19-24

Nitithamyong, P., \& Skibniewski, M. J. (2006). Success/failure factors and performance measures of web-based construction project management systems: professionals' viewpoint. Journal of Construction Engineering and Management, 132, 80-87

Pena-Mora, F., \& Dwivedi, G. H. (2002). Multiple device collaborative and real time analysis system for project management in civil engineering. Journal of Computing in Civil Engineering, 16, 2338

Philbin, S. P. (2008a). Managing complex technology projects. ResearchTechnology Management, 51, 32-39

Philbin, S. P. (2008b). Big management: a systems engineering approach. Journal of High Technology Management Research, 19, 114-127

Philbin, S. P. (2010). Developing an integrated approach to system safety engineering. Engineering Management Journal, 22(2), 56-67

Philbin, S. P. (2011). Application of Systems Engineering and Systems Thinking to Project Management. In Collins R, J. (Ed.), Project Management. New York: Nova Science Publishers

Philbin, S. P., \& Kennedy, D. A. (2014). Diagnostic framework and health check tool for engineering and technology projects. Journal of Industrial Engineering and Management, 7, 1145-1166

Raz, T., \& Michael, E. (2001). Use and benefits of tools for project risk management. International Journal of Project Management, 19, 9-17

Reich, B. H., Gemino, A., \& Sauer, C. (2012). Knowledge management and project-based knowledge in it projects: a model and preliminary empirical results. International Journal of Project Management, 30, 663-674

Reyck, B. D., Grushka-Cockayne, Y., Locket, M., Calderini, S. R., Mour, M., \& Sloper, A. (2005). The impact of project portfolio management on information technology projects. International Journal of Project Management, 23, 524-537

Ring, M. J. (2000). A billion-dollar big big blunder. Tech, 120, 5-7

Sabherwal, R. (1999). The role of trust in outsourced IS development projects. Communications of the ACM, 42, 80-86

Sadeh, A., Dvir, D., \& Shenhar, A. (2000). The role of contract type in the success of R\&D defence projects under increasing uncertainty. Project Management Journal, 31, 14-22

Sage, A. P., \& Rouse, W. B. (2009). Handbook of Systems Engineering and Management. New York: John Wiley \& Sons, Inc.

Schon, D. (1983). The Reflective Practitioner: How Professionals Think in Action. [sine loco]: Basic Books, Inc.

Schwalbe, K. (2013). Information Technology Project Management. [sine loco]: Cengage Learning

Sivarajah, U., Lee, H., Irani, Z., \& Weer-akkody, V. (2014). Fostering smart cities through ICT driven policy-making: expected outcomes and impacts of DAREED project. International Journal of Electronic Government Research, 10, 1-18

Standish Group. (1995) and (2009). The CHAOS report. Retrieved from http://www.standishgroup.com/

Straus, S., Tetroe, J., \& Graham, I. D. (2013). Knowledge Translation in Health Care: Moving from Evidence to Practice. New York: John Wiley \& Sons, Inc.

Sunindijo, R. Y., Hadikusumo, B. H., \& Ogunlana, S. (2007). Emotional intelligence and leadership styles in construction project management. Journal of Management Engineering, 23, 166-170

Turner, J. R., \& Muller, R. (2005). The Project Manager's Leadership Style as a Success Factor on Projects: a Literature review. [sine loco]: Project Management Institute 
Weick, K. E., Sutcliffe, K. M., \& Obstfeld, D. (2005). Organizing and the process of sense making. Organization Science, 16, 409-421

Yang, L. R., Chen, J. H., \& Wang, H. W. (2012). Assessing impacts of information technology on project success through knowledge management practice. Automation in Construction, 22, 182-191

Yazici, H. J. (2009). The role of project management maturity and organizational culture in perceived performance. Project Management Journal, 40, 14-33 